\title{
What Do You Expect? \\ A Reconfiguration of the Audit Expectations Gap
}

\section{Ian Dennis \\ Oxford Brookes University Business School}

This paper undertakes a conceptual enquiry into the idea of the expectations gap. This method of enquiry is explained as a philosophical investigation into the concepts used in the literature relating to the expectations gap. A descriptive conceptual enquiry is undertaken into the current use of the expression 'expectations gap' and the related terms 'expectation' and 'expects'. It is argued that vagueness and misunderstandings of the uses of these expressions undermines a grasp of the issues involved and of how they are to be resolved. The paper looks at the various explanations of these expressions in the literature and suggests that more clarity in discussions of the issues would be achieved by characterizing expectations as beliefs about what auditors do or desires for them to perform certain procedures with certain qualities in audits. The grounds for the beliefs are considered. The belief that the auditor will do something because of a belief that it is a duty is examined. The way in which the auditor's beliefs that something is a duty determines what they do is explained through the idea of practical reasoning. The paper goes on to explore the suggestion that an expectation might also be some kind of desire that auditors perform certain actions in the context of an audit. These desires are related to a consideration of the objectives of auditing. The idea of the reasonableness of these desires is examined. The reasons for wanting auditors to undertake particular procedures can also underlie the acceptance of particular meanings of 'audit' and 'auditing'. The audit expectations gap is reconfigured in terms of the beliefs and desires identified in the paper.

Key words: Auditing, conceptual enquiry, expectations gap, objectives of auditing.
Correspondence to: $\mathrm{Dr}$ Ian Dennis, Senior Lecturer in Accounting and Finance, Oxford Brookes University Business School, Wheatley Campus, Wheatley, Oxford OX33 1HX, UK.

Email: iddennis@brookes.ac.uk

\section{SUMMARY}

This paper undertakes a conceptual enquiry into the idea of the 'expectations gap'. The method of conceptual enquiry is explained. A descriptive 
conceptual enquiry is undertaken by reviewing explanations of the expression 'expectations gap' in the literature. Although there are a number of ways of characterizing the gap, many of these explain the gap as involving differences in beliefs about what auditing involves and/or in desires that auditors perform certain functions in particular ways. The nature of expectations is examined by exploring these beliefs and desires. Different grounds for these expectations are identified. Beliefs about what auditors do may be based on empirical beliefs about the duties of auditors. The grounds for desires are explored using the notion of practical reasoning. A desire that auditors perform actions or perform them in particular ways may be derived from other desires for auditing or auditors to achieve certain objectives. The paper also examines whether expectations about auditing might be derived from a consideration of the meaning of 'auditing'. It is suggested that definitions of 'auditing' may themselves result from wanting to achieve certain ends or objectives in auditing situations. It is suggested that the 'expectations gap' may be reconfigured by eliminating the reference to expectations and treating the issues as involving either beliefs and/or desires of the kind identified. Clarifying the nature of expectations in this way will facilitate greater clarity in discussion of the expectations gap and more meaningful argument about the grounds for these expectations. The paper ends with speculation that the failure to distinguish different kinds of expectation might have arisen because the auditing profession chooses to mask disagreements about what is wanted from auditing by treating them as though they arise from beliefs about the nature of auditing.

\section{THE 'EXPECTATIONS GAP'}

The objective of this paper is to undertake a conceptual enquiry into the idea of an expectations gap in auditing. It examines the meaning of the expression 'expectations gap' and elucidates the nature of expectations. Corporate collapses such as Enron and WorldCom are often followed by a chorus of blame. Auditors are castigated for not having warned shareholders and other interested parties about the precarious financial position of the companies that have failed or for failing to detect frauds that contributed to the collapse. Questions like 'Why did the auditors not warn us that the company was not a going concern?' or
'Why did the auditors not detect fraud?' are asked. It is clear from these questions the auditor was expected to discover going concern problems or the fraud during their audit. The fact that the auditors do not meet these expectations gives rise to 'concern' about auditing that is expressed through the 'notion of the "audit expectations gap"' (Humphrey, 1997, p. 3). The gap has a long history fuelled by such financial scandals (Humphrey et al., 1992a, p. 6). It is 'one of the most serious issues facing auditing practitioners and regulators today' (Humphrey et al., 1992a, p. 1). Unfortunately, although the term 'audit expectations gap' remains in common usage it is 'relatively ill-defined and can be taken to cover a variety of facets of the relationship between auditors and other groups' (Humphrey et al., 1992a, p. 2). ${ }^{1}$ A conceptual enquiry examines the use of the expression 'expectations gap' in order to identify this 'variety of facets' and to suggest a different way of characterizing it. The meaning of the expression is explored by asking the question 'what do you expect?'. The point of the question is not to identify specific expectations. This is well explored in the empirical work relating to the expectations gap. The question is designed to elucidate the meaning of the expression 'expectations gap'. The issues that are raised in the debate can be properly addressed only if the nature of the expectations is understood and the reasons for these expectations explored.

The paper begins by explaining what is involved in a conceptual enquiry and why it is important to undertake such an enquiry. This constitutes the method of the paper. A conceptual enquiry is then undertaken into how the expression 'expectations gap' is understood in the literature. It considers explanations of the expression and how the expression is used in the literature. The nature of expectations is examined with some help from philosophy. The idea that expectations are beliefs is explored. Reasons for such beliefs are considered. The grounds for beliefs include believing that auditors will do something because it is a duty of auditors to undertake certain auditing procedures and to demonstrate certain qualities in their performance. Another characterization of expectations as desires is then examined. These constitute the reasons why regulators establish duties that auditors are required to discharge. The reasons for wanting auditors to perform certain duties and the idea that such desires are reasonable are examined. The paper ends with a reconfiguration of the audit expectations gap based 
on the analysis of the kinds of expectations identified in the paper.

\section{CONCEPTUAL ENQUIRY}

In modern philosophy a conceptual enquiry is understood as an enquiry into the meaning of words or expressions. A 'descriptive conceptual enquiry' in accounting looks at 'how accountants use their terms' (Lyas, 1993). A conceptual enquiry answers questions about expressions such as 'do they have a precise meaning? Are they consistently used? Are they ambiguous?' (Lyas, 1993, p. 156). It is a form of philosophical enquiry. Lyas argues that 'any discipline which uses concepts, including accounting, will have a philosophical dimension' and that 'no discipline worth bothering about can seek to evade such conceptual enquiries'. They 'constitute the hygiene of the reasoning of a discipline. Without them we are prey to the loose, the ambiguous, and the down-right slovenly' (Lyas, 1993, p. 156). The nature of conceptual enquiry is further explained by Dennis (2008).

This paper undertakes a descriptive conceptual enquiry into the expression 'expectations gap'. It examines the use of this expression by those who debate, discuss and write about the subject. The reason why such an enquiry is important is suggested by Wittgenstein. He once observed that 'concepts lead us to make investigations; are the expression of our interest, and direct our interest' (Wittgenstein, 1958, §570). Our interest can also be misdirected by concepts. Sterling draws attention to 'philosophers' appreciation of the connection of clarity of language to clarity of thought (and communication)' and suggests that 'accountants seem to lack such appreciation and the result is the perpetuation of a number of errors and fallacies that can be traced to linguistic turbidity' (Sterling, 1993, p. 127).

In the observation that the term 'expectations gap' is 'ill-defined' noted above, Humphrey suggests that problems of 'linguistic turbidity' may have infected discussions about the expectations gap. If the expression 'expectations gap' is not consistently used and if different people mean something different by the expression then communication and debate is undermined. The expression is vague. This means that there is 'in the practice of its application, significant disagreements about what uses of it are correct' (Baker \& Hacker, 1980, p. 218). The consequences of this are that it is difficult to agree on the truth of empirical statements about expectations or to debate different expectations since people mean different things by these expressions. The paper explores the extent to which this is the case.

Vagueness can be eliminated through an 'evaluative conceptual enquiry'. The use of the expression 'expectations gap' is evaluated in the sense that the usefulness of the concept in the auditing context is questioned. A further 'prescriptive conceptual enquiry' might then go on to reject certain meanings or concepts on the grounds that they are not useful and to propose a preferred meaning. The term might be abandoned if the confusion in its use cannot easily be remedied (Dennis, 2008). These kinds of enquiry make sense if language is conceived of as 'naturalistic'. This view was adopted by Wittgenstein who argues that concepts emerge within a context. To understand the meaning of any term is to grasp 'those human interests, needs and practices in the context of which it arose and into which it fits' (Lyas, 1993, p. 163). If the context is a particular society then it follows that meanings are 'socially constructed' and 'depend on human agreement' (Searle, 1995, p. 2). A conceptual enquiry can hopefully influence meanings in order the make the expressions or concepts more useful. This is the justification for undertaking such an enquiry.

\section{A DESCRIPTIVE CONCEPTUAL ENQUIRY INTO 'EXPECTATIONS $\mathrm{GAP}^{\prime}$}

The literature on the expectations gap is 'extensive, ranging for example, from empirical and experimental research to ascertain beliefs about auditing and its effects on the decision of particular groups to analysis of legal judgement and to the work of various professional and governmental investigations established to consider audit related issues' (Humphrey et al., 1993, p. 395). The paper does not pretend to examine all of this literature. It is mainly concerned with the current use of the expression 'expectations gap' and is interested in the historical literature only in so far as this provides some insight into the current usage of the term. It is not meant to provide a complete 'history of concept formation' or to review all of the previous uses of the term. The current debate about auditing expectations is 'directed' by the current understanding of the expression. Historical uses of the expression play a part in determining such understanding. Indeed, 'the issues incorporated 
within the term "audit expectations gap" (such as auditors' fraud detection responsibilities, auditor independence, public interest reporting and the meaning of auditors' communications) have remained very similar since its emergence in the 1970s, and, indeed have a history that is as long as company auditing itself' (Humphrey et al., 1992a, p. 5). If the issues are the same then the kind of thing that is understood by the term 'expectations gap' would not appear to have changed.

The use of the expression 'expectations gap' is common in current discussions of regulators, preparers of financial statements, the profession and academics. However, it is characterized in different ways and the nature of the expectations is not always clear. The President of the International Federation of Accountants (IFAC) recently stated that 'despite the audit reforms of the past five years, I believe an expectation gap still exists between what an audit actually is, and what investors and other stakeholders think it should be (IFAC, 2007, p. 6). This sounds like a definitional issue about the meaning of 'audit' but it might also indicate beliefs about what auditors do in the context of an audit or what actually occurs in an audit. Alternatively what stakeholders 'think it should be' might be interpreted as a matter of what they want auditors to do. It is thus not clear whether expectations are beliefs, facts or desires. The 'gap' might be between the beliefs or desires that one party has and the beliefs and desires that another party has, or between a belief and the facts that make the belief true or false. The Auditing Practices Board (APB) refers to their own work on proposals for expanding the auditor report as being 'intended to address that aspect of the expectations gap that arose because users of auditor's reports did not understand the scope and nature of the audit' (APB, 2007, p. 10). The reference to understanding suggests that the users may have false beliefs about what an audit involves. The ICAEW Audit Quality Forum, which includes representatives of auditors, investors and business and regulatory bodies, recognizes that there are expectations gaps between what some stakeholders want or believe to be the purpose of the audit and what auditors are providing to existing shareholders by way of assurance' (ICAEW, 2006a, p. 5). Reference is made here to both beliefs and desires and also to facts that render the beliefs true or false. It might be understood as indicating a 'gap' between what is desired and whether that desire is fulfilled or not. The current syllabuses of the Professional Stage examinations of the ICAEW include the requirement to consider the gap between outcomes delivered by audit engagements and the expectations of users of audit reports' (ICAEW, 2006b). Here there is reference to facts but it is not clear whether the expectations are beliefs about the audit report or desires about what it should contain.

It is not surprising that there is a diversity of meanings in the current usage of the expression 'expectations gap'. A similar diversity is evident in historical uses of the term (Humphrey et al., 1992a, 1992b; Humphrey, 1997). In summary the gap is 'a representation of the feeling that auditors are performing in a manner at variance with the beliefs and desires of those for whose benefit the audit is being carried out' (Humphrey, 1997, p. 9). It is not surprising that current talk about the expectations gap refers to a gap in beliefs, desires and facts given the historical uses of the expression.

Humphrey analyses the expectations gap as 'a role-perception gap, leading to comparisons of the views of shareholders ... regarding the role of the audit with a predetermined, sometimes legalistic notion of what can reasonably be expected of auditors (or with what auditors believe should be expected of them)' (Humphrey, 1997, p. 9). There are a number of different ways in which this could be understood. A gap might arise between what shareholders believe auditors do and what they are required to do by law. This is a gap between beliefs and facts that make the belief true or false. It might relate to what shareholders believe auditors do and what auditors believe that they are required to do by law, that is, a gap between different beliefs. It might also relate to a gap between what shareholders want auditors to do and what auditors want to do. These different 'expectations' are conflated in the idea of a 'performance gap'. This is explained as a difference between 'what society can reasonably expect auditors to accomplish and what they are perceived to achieve' (Porter, 1993, p. 50). It is not clear though whether the 'perception' of shareholders regarding the role of auditors is a belief about what auditors do or a desire that they perform some role.

The reference to what can 'reasonably' be expected of auditors cannot really be understood unless it is clear whether the expectation is a belief that is reasonable or a desire that is reasonable. If the expectation is a belief then it is appropriate to talk about an 'ignorance gap'. The answer to such a gap is to educate the recipients of audit services as 
to what it is reasonable to expect from an audit. A belief is reasonable if it is based on fact. If the gap is not in beliefs but in desires then the response that addresses ignorance is inadequate. Arguing about beliefs is different from arguing about desires. This is explored further below.

If the nature of the expectations is not agreed then arguments between parties about them might be at cross purposes. A gap in desires should be addressed by considering the arguments for or against conflicting desires. Whether the desires are reasonable or not depends upon the 'reasonableness' of the reasons for wanting auditors to do something or for believing that something is the case. If they are not reasonable there might be a 'reasonableness gap'. This has been explained as a gap 'between what society expects auditors to achieve and what they can reasonably be expected to accomplish' (Porter, 1993 , p. 50). However, unless it is clear whether the expectation is one of belief or of desire, then the nature of the 'reasonableness gap' hangs in the air because the nature of the reasons for the 'expectation' is not clear.

There may be concerns about 'the adequacy of current professional auditing standards and the quality of auditors' service delivery' (Humphrey, 1997, p. 9). Two separate issues are conflated in this description of the expectations gap. It might be that current auditing standards are inadequate because they do not require auditors to do something that someone else wants them to do. This might be called a 'deficient standards gap' and could be explained as 'a gap between the duties which can reasonably be expected of auditors and auditors' existing duties as defined by the law and professional promulgations' (Porter, 1993, p. 50). The reference to 'reasonable' suggests that the gap is not just in what is wanted by different parties but that there may be a gap in reasons for wanting it. It might also be that auditors do not follow the standards adequately in delivering their service. If it is a matter of fact as to what the existing duties actually are, then is this a gap between desires and reality? The latter might be called a 'deficient performance gap'. This might be explained as 'a gap between the expected standards of performance of auditors' existing duties and auditors' perceived performance, as expected and perceived by society'. This gap might involve perceptions about the quality of auditors' work (Humphrey et al., 1992a, p. 2). Once again, this can be understood as either a gap in beliefs about the actual quality of their work or in desires that they perform them in a certain way. These are sometimes lumped together in talking about the " "expectations" controversy over the social role of auditors' (Gaa, 1991, p. 85). Having expectations about the 'social role of auditors' might be understood as beliefs or desires about role or quality.

Sikka et al. explain the gap as a difference in objectives. It is the gap 'between what the public expects from an audit' and 'what the auditing profession prefers the audit objectives to be' (Sikka et al., 1998, p. 299). The importance of clarifying the objectives of auditing was emphasized by Lee (1970) even before the term 'expectations gap' relating to auditing was first used. He pointed to 'lack of real understanding of the auditor and his work' that is apparent in some criticism of the audit function that is made following audit scandals (Lee, 1970, p. 292). The public might 'expect' auditors to do something because they believe that they are required to do it. If this is the case then it is not appropriate to talk about a gap between this and what the auditing profession 'prefers' the audit objectives to be. This is a matter of what the profession wants the regulator to require them to do, not about what they believe that they have to do. It is not a gap in beliefs but a gap between beliefs and desires. If this is what is meant then it is as inappropriate to talk of a 'gap' as to talk of a 'gap' between chalk and cheese. It would be appropriate to talk about a gap if there was a difference between what the public want auditors to do and what auditors want auditors to do or between what the public believe auditors do and what auditors believe they do.

These different understandings suggest that the terms are vague. Some help in understanding the nature of 'expectations' can be derived from philosophical sources.

\section{EXPECTATION}

The expressions used to describe the expectations gap such as ' $X$ expects that ...', 'X believes that ...', ' $X$ desires that ...', etc. are known, following the terminology of the philosopher Bertrand Russell, as statements about propositional attitudes (Wolfram, 1989, p. 70). Propositional attitudes report that a person $X$ has a certain attitude designated by the expression that precedes 'that' towards a proposition that follows 'that'. The proposition is not asserted in the sense that the truth of the 
statement that someone has a propositional attitude does not depend upon the truth of the embedded proposition (Wolfram, 1989, p. 139). For example, it may be true that someone believes that cats can fly even though the proposition 'cats can fly' is false. Similarly, it might be true that someone expects something of auditors without it being the case that auditors actually do what is expected.

In ordinary language the word 'expectation' or 'expects' implies that the 'expectation is unsatisfied, because it is the expectation of something' (Wittgenstein, 1958, §438). If something is expected then it is yet to happen. In an example that Wittgenstein uses, a person might say 'I see someone pointing a gun and say "I expect a report". The shot is fired.' (Wittgenstein, 1958, $\S 442)$. The expectation might be re-expressed as 'I expect that an explosive noise will occur when the trigger is pulled'. The event of pulling the trigger or firing the shot has not yet happened. Expectations like the one about the report of the gun are really beliefs about the future. Given that the sentence that follows 'that' when an expectation is expressed is not a description of an event that has happened, this sentence is neither true nor false. What is true or false is that someone has the expectation in question. There may be a 'gap' in expectations where someone has an expectation or belief and someone else does not have the same expectation or belief. A different kind of gap exists where someone has an expectation and yet what is expected does not happen. If what is expected does happen then the expectation is fulfilled. A sentence that describes the event becomes true. If not, then the expectation has not been met. If someone expects something to happen and it does not happen, then this might be described as a 'gap' in expectations. This only means that a belief that some event will occur in the future turns out to be false.

In the descriptions of the expectations gap considered in the descriptive conceptual enquiry above, both of these kinds of gaps were referred to. There may be a gap between what one party expects auditors to do and what another party expects auditors to do, that is, a gap in the propositional attitudes of the two parties. If the expectation is a belief about what will happen then one party has such a belief and another party does not have such a belief. It might also be the case that what is expected to happen in an audit is different from what actually happens. This might be described as a 'gap', but it is not a gap in propositional attitudes but between the belief expressed in the embedded sentence and certain facts about what happens.

Both of these 'gaps' are evident in one example from the expectations gap literature concerning the expectations relating to the auditors' role in detecting fraud. Arguments about 'the extent of auditors' responsibility for detecting and preventing fraud' have a long history. It has received 'arguably, as much attention in the 1890s as it has done in the 1990s' (Chandler \& Edwards, 1996 , p. 12). There is a long history of differences of opinion between jurists and auditors and also among them as to the role of auditors in detecting fraud (Teo \& Cobbin, 2005). Similar differences are evident in more recent empirical work on the expectations gap. This suggests that 'the issue of fraud detection is likely to remain a source of debate' (Humphrey et al., 1992a, p. 36). This expectation might be expressed by a sentence uttered by an interested party 'I expect that auditors of company $X$ will detect fraud during their audit'. The kinds of fraud that auditors are expected to detect, whether all fraud or all material fraud or employee or senior management frauds, can be further specified. If the expectation is of the belief kind, it might also be expressed as 'I believe that auditors of company $\mathrm{X}$ will detect fraud during their audit'. Where some parties have such a belief and others do not then there is a 'gap' in beliefs, that is, in the propositional attitude. One party has the belief and another party does not.

If parties have different beliefs then it is important to investigate the grounds or reasons for having such beliefs. In Wittgenstein's example, someone might expect a 'report' because they are aware of what guns are and know, from past experience, what happens when a gun is fired. Expectations that are beliefs about what will happen might be based on beliefs about what has happened. Exploring a reason for a belief is a matter of looking at the reasoning to the belief. As Wittgenstein points out, the concept of a reason is related to that of reasoning (Hacker, 1996, p. 58). Giving reasons for believing is a matter of expressing premises that are believed and that are used in reasoning to a conclusion that is also believed. In the case of an expectation of this kind, the belief amounts to a prediction that something will happen. Justifying a belief or prediction about something that has not happened is a matter of giving reasons or grounds for believing that it will occur. What kind of reasons and reasoning might justify an expectation of the belief kind? 
It may be based on inductive reasoning where a conclusion that something will occur is based on premises about what has occurred in the past (Gillies, 1993, pp. 8-11). If the auditors of company $X$ have always been observed to detect fraud in the past, then they might be expected to do so in the future. The belief about what auditors will do might be based on what other auditors have done. They might believe a universal generalization that all auditors detect fraud. This is unlikely given that there are clear instances in the past where particular auditors have failed to detect fraud in prominent cases of corporate collapse. Given these cases, it is unlikely that anyone actually believes such a universal generalization. It is clearly false. They might believe a statistical statement to the effect that most auditors detect fraud might constitute a reason for believing that the auditors of Company $\mathrm{X}$ will do so.

The expectations gap might be characterized as a difference in beliefs about the actions of particular auditors. One party might believe that the auditors of Company $X$ will detect fraud and another party might believe that they will not. However, the expectations gap issues are not normally specified at this level of particularity. Expectations are characterized more generally. Although particular lapses in the detection of fraud by auditors are cited as evidence of a failure in expectations, what is really at issue is the generalization, that is, the grounds for particular beliefs. This is why characterizing the issues as an expectation is misleading. The beliefs about auditors are not just related to the future. Some of the gaps arise because of different beliefs about what auditors generally do, in the past and present as well as in the future. Some party might believe that auditors generally detect fraud and another party might not believe it.

If the expectations gap arises through acceptance of a statistical generalization, it is difficult to see why evidence that particular auditors fail to detect fraud should be taken by anyone to support or undermine the belief in the generalization. After all, although the statistical generalization states that most auditors detect fraud, it also implies that not all auditors do so. If particular auditors do not do so then this is to be expected. It is only if it happens often that the statistical generalization is refuted. Although differences in beliefs about what auditors will do might result from different parties either accepting or rejecting statistical statements, there is some empirical evidence that the expectation is based on a belief about the duties of auditors.

\section{DUTIES OF AUDITORS}

Humphrey et al. state 'a number of interviewees took the statutory provisions contained in the Companies Acts as their starting point for describing the function of auditing' and 'this legalistic approach was certainly apparent in the views of many of those involved in regulatory functions as well as the lawyers interviewed' (Humphrey et al., 1992a, p. 32). This suggests that the reason parties have for believing that auditors will detect fraud is not based on beliefs in statistical statements derived from experience about what auditors have done in the past, but on a belief that fraud detection is a duty of auditors coupled with a belief that auditors will do their duty. Porter uses statute law, case law and professional promulgations to identify the duties of auditors and then asks the respondents to state whether or not it is an existing duty (Porter, 1993, p. 50). Getting respondents to identify duties of auditors suggests that researchers assume that people who have expectations about auditors base these expectations on beliefs about the duty of auditors.

If the expectation that auditors will do something is of the belief kind then believing that a particular procedure is a duty of auditors may constitute a ground for expecting or believing that they will do it. Someone with this belief may reason as follows:

Premise 1: I believe that $\mathrm{X}$ is a duty of auditors.

Premise 2: I believe that auditors always do their duty.

Conclusion: I believe that auditors will do X.

Someone else might reason differently. They may have different beliefs about whether $X$ is a duty of auditors or whether auditors always do their duty. There may be a 'gap' in these beliefs in the sense that one person may believe something and another person may not believe it. As a result they may end up with different beliefs, that is, may draw a different conclusion about what auditors will do in an audit. In other words, premise 1 is not agreed. There is plenty of empirical evidence that beliefs about the duties of auditors are mistaken. In earlier research, Lee asked three audit oriented groups, auditors, auditees and audit beneficiaries, about a range of audit 'objectives' that 'have been either advocated, prescribed, accepted or rejected as company audit objectives during the last eighty years or so' (Lee, 1970, p. 295). Lee seems to use the 
term 'objectives' to mean things like expressing an opinion on whether financial statements give a true and fair view, detecting fraud and compliance with legal requirements. The difference between objectives and duties is only that 'objectives' are more general. These general duties might be contrasted with more specific duties to perform certain procedures that will result in fulfilling the general ones. Lee concludes that the viewpoints expressed by professional and industrial accountants were surprisingly ill-formed' (Lee, 1970, p. 295). This conclusion is confirmed by more current research that asks about a wider range of tasks. Auditees, financial and non-financial community audit beneficiaries were found to be mistaken in their beliefs about the duties of auditors. The non-financial community audit beneficiaries 'considered auditors' duties to be far more extensive than were actually required' (Porter \& Gowthorpe, 2004, p. 19). Rectifying a mistake of this kind, that is, an 'ignorance gap', is a matter of educating such parties about the duties of auditors.

A failure to agree on the conclusion might also result from accepting or not accepting premise 2 . This appears to be a belief about an empirical statement, a generalization about what auditors always do, namely, their duty. Given audit scandals like Enron, it seems unlikely that anyone would accept premise 2 as it stands. Auditors do not always do their duty. It is more likely that interested parties only accept a statistical statement of the kind 'I believe that auditors almost always do their duty'. If this is the case the conclusion would not be as stated above but as 'I believe that auditors will almost always do $X^{\prime}$. A belief of this kind is not undermined by the occasional failure of auditors to do their duty. As with statistical statements above, this is entirely to be expected.

Even with this change from a universal to a statistical generalization it is unlikely that interested parties actually argue like this. Something may be a duty of auditors, but unless auditors are aware that it is a duty then they will not do it. What is needed is another premise, namely 'I believe that auditors always do what they believe to be their duty'. The trouble is that the reasoning to a belief about what auditors will do becomes unsound if premise 2 is altered. What is needed is the addition of another premise for the argument above to go through:

Premise 1: I believe that $X$ is a duty of auditors.
Premise 2(a): I believe that if $X$ is a duty of auditors then auditors will believe that it is their duty.

Premise 2: I believe that auditors always do what they believe to be their duty.

Conclusion: I believe that auditors will do X.

There is plenty of empirical evidence that auditors do not always believe that something is their duty even if it is their duty. Empirical work from the time of Lee (1970) to Porter \& Gowthorpe (2004) shows that auditors sometimes fail to recognize existing duties. Lee observed that it is extremely disappointing to see accountants, and especially auditors, displaying beliefs about auditing as apparently mistaken as some of those expressed by so-called laymen' (Lee, 1970, p. 296). More recently the auditor group failed to recognize 'seven of their existing duties' (Porter \& Gowthorpe, 2004, p. 14). This shows that the belief in premise 2(a) is false. This may be an 'ignorance gap' in that beliefs may be false, but it is one that affects auditors as well as other interested parties.

If auditors do not believe that something is their duty, even if it actually is their duty, the effect will be that they will not end up doing their duty. The assumption here is that auditors act for reasons and these reasons involve beliefs about what is their duty. Auditors reason as follows:

I want to do my duty.

I believe that $\mathrm{X}$ is my duty.

Therefore, I want to do X.

They may then go on to act because they want to do X. They end up doing their duty. If they do not believe $X$ is their duty then they do not conclude that they want to do $X$ and, therefore, they do not end up doing $X$. What this shows is if the auditor has a different belief as to what their duty is from that of some other party, then the belief that an auditor will do $X$ most of the time is likely to be false. There is a gap between the belief and reality. What this shows is that differences in beliefs about what is a duty of auditors can result in a 'gap' in beliefs about what auditors will do but also to a 'gap' between the belief and the reality. It is no wonder that the literature on the expectations gap sometimes characterizes the gap in terms of a gap in propositional attitudes, in the belief itself, but also a gap between beliefs and reality. 
If expectations are beliefs then the expectations gap might be characterized as a gap between:

(i) beliefs of various parties in statistical generalizations about what auditors mostly do

(ii) beliefs of various parties about what is the duty of auditors

(iii) a belief about what will happen and what happens in reality.

The beliefs in (i) might be based on the beliefs in (ii) in so far as the parties believe that auditors mostly do something is based on a belief that it is their duty to do so and that auditors mostly do their duty. If auditors have different beliefs about their duties then they may end up not doing what they are believed to mostly do and (iii) arises as a result.

Characterizing the expectations gap as gap in beliefs suggests that it is an 'ignorance gap'. If the belief that $X$ is a duty of auditors is mistaken then the parties, including auditors, can be educated by explaining what is required of auditors by law or professional regulation. Lee suggests 'in order to fully appreciate what the company auditor is doing on their behalf, shareholders - and, for that matter, other users of the accounts - must know what the detailed objectives of the audit are. This knowledge and understanding can only come from well defined and adequately communicated statements describing the appropriate audit objectives of the day' (1970, p. 292). This should deal with false beliefs in premise 1. If auditors do not grasp their duties then they too can be educated in what their duties are. This should assist in making the belief in premise 2(a) true. If auditors believe that something is their duty and they want to do their duty, then they should end up doing their duty for the most part and there will not be a gap between belief and reality. If this is done then the expectations gap should disappear.

This sounds rather too good to be true. The issues raised by the gap may not arise solely because of beliefs about what the duties of auditors actually are. It may be that the gap is also about what the auditors' duties should be. It may be that it is 'something more than a communication problem' (Humphrey et al., 1992a, p. 8). The expectations about fraud detection 'may be expressing wider ethical beliefs about business and audit' (Humphrey et al., 1992a, p. 36). In fact, it would be more accurate not to talk in terms of beliefs, whether 'ethical' or not, but to talk instead about what is wanted from auditing. The propositional attitude that is referred to as an expectation may not be a belief about what auditors will do or about their duties, but a desire that auditors do something or that something becomes a duty of auditors. Bridging the expectations gap is not just a matter of dealing with the reasons for believing that auditors will do something or that something is a duty, but of considering reasons for wanting auditors to do something or for something to be made a duty.

\section{EXPECTATIONS AS DESIRES}

In ordinary uses of the term 'expects' the propositional attitude is not necessarily a belief but might be understood, at least in part, as a desire. There is an interesting example from history. Admiral Nelson communicated an expectation to his fleet before the Battle of Trafalgar. Using flags he signalled to his ships 'England expects that every man will do his duty'. Is this expectation a belief? Apparently, Nelson originally wanted his signal officer to send the message 'England confides [=has confidence that] every man will do his duty' (Wikipedia, 2008). This suggests that Nelson's expectation was in the nature of a belief, but did he really believe that every man would do their duty or merely that most men would do so? The actual message sent replaced 'confides' with 'expects'. This was done because in the signal book the word 'confides' would have to be spelled out letter-by-letter whereas there was a single symbol for 'expects' (Wikipedia, 2008). The change saved time, but also altered the meaning. The message sent conveys not only the fact that it is believed that at least most men will do their duty, but it also expresses the hope or desire that the proposition becomes true. It is thus an expression not only of belief but also of a desire.

Some of the statements of expectations by those who participate in the expectations gap discussions might also be interpreted as expressions of desires as well as, or instead of, beliefs. The statement 'shareholders expect that most auditors will detect fraud' might be interpreted as a belief about what auditors generally do, perhaps based on a belief that it is their duty to do so, but might also be interpreted as an expression of a desire that auditors should have such a duty. These expectations might be more perspicuously expressed by stating that 'shareholders believe that it is a duty of auditors to detect fraud' and/or that 'shareholders want auditors to detect fraud'. How it is to be interpreted would be revealed by how the 
expectation is justified. What kind of premises and what kind of reasoning are used in giving reasons for or justifying such expectations? Reasoning to a belief that auditors will do something might be based on premises about duties of the kind indicated above. This is different from the kind of reasoning that justifies or explains a desire. This is practical reasoning.

\section{PRACTICAL REASONING}

Practical reasoning is often explained in the philosophical literature in the context of explaining what is involved in giving reasons for intentional actions (Anscombe, 1957). Explaining an action is a matter of showing that the action follows from certain premises in accordance with practical reasoning. A reason for an action 'rationalizes an action if it leads us to see something the agent saw, or thought he saw, in his action - some feature, consequence, or aspect of the action the agent wanted, desired, prized, held dear, thought dutiful, beneficial, obligatory, or agreeable' (Davidson, 1980, p. 3). They can be subsumed under the broad idea that the action was wanted or desired. This does not have the implication that it was 'intense or emotion-laden' (Goldman, 1970, p. 49). Part of the reason expresses a desire or objective that is to be achieved by the action in question. The other constituent of a reason is a belief that states that the action in question will fulfil the desire or objective. The pair is called the primary reason, or reason for short, why the agent performed the action (Davidson, 1980, p. 4). Practical reasoning includes a premise that expresses a desire and a premise that expresses a belief. It concludes with an intention to act in a certain way. An example of such reasoning would be of the form:

I want $Y$

I believe that doing $X$ will fulfil $Y$

I will do X.

This was the kind of reasoning described above whereby auditors were taken to reason from a desire to do their duty and a belief that something is their duty to a desire to do what is their duty. The reasons explain why they performed certain intentional actions in the context of their audit.

This kind of reasoning is also known in the accounting literature as 'instrumental reasoning' or 'conditional-normative reasoning' (Mattessich, 1995) or as 'means-end reasoning' (Archer, 1993).
Although the conclusion is expressed as an intention to perform an action, it actually expresses a desire to perform an action. Practical reasoning should really be understood as reasoning from desires and beliefs to another desire. In the case of actions it is a desire to act. The conclusion 'I will do/intend to do $X$ ' might be expressed as 'I want to do $X^{\prime}$. If the act follows, this is because it is wanted. This is a different kind of explanation than giving reasons for wanting to do something. It might be interpreted as explaining the action that follows by stating that the cause of the action is the fact that someone wants to perform the action. Even if someone wants to perform an action, they may not do so. This may be because they are physically prevented from doing so. It may also be because they want to do something else more than they want to do X.

If an expectation is understood as a desire then an expectation gap might arise if one party desires something that another party does not. Arguing about expectations would be arguing about reasons for wanting to do something. In practical reasoning these reasons are the expression of a desire for something other than the action and a belief that performing the action in question will fulfil the desire. If someone believes that performing an action will result in the fulfilment of this other desire then evidence for this belief can be disputed. If the belief follows from some generalization then the generalization can be disputed. To take an example, an accountant may argue that they want to audit the books of Company A because they want to earn a living and believe that Company A will pay them for auditing their books. The belief that Company A will pay an auditor for auditing their books might be disputed by pointing out that Company A never pays its auditors. Arguing about desires is less easy to understand. If there is a disagreement about the desire premise then is any further argument possible? Is it not simply a brute fact that one person wants something that another person does not want? Although this might be the case, there are plenty of instances where it is possible to argue about desires. There may be further reasons for the desire in question. In the same example above, someone may question why the auditor wants to earn a living. This is unlikely because most people already understand that this is something desirable. However, if this was not agreed then the auditor might argue that they want to be able to pay for their children's schooling and believe that by 
earning a living this will be possible. These reasons are set out in further practical reasoning where from the desire to pay for schooling and the belief that earning a living will make this possible the desire to earn a living follows.

It was assumed in the practical reasoning of an auditor above that desires that underpin auditing actions are desires of auditors to do their duty. If auditors want to do their duty and believe that something is a duty of auditors then they might conclude that they want to do that thing. They may want to do their duty simply because they accept the obligation or because they do not want the opprobrium of being seen not to observe the law or professional regulations. If they do not do their duty they may be excluded from the profession or find themselves subject to charges of negligence where doing what the profession requires is a criterion of not being negligent. These may all constitute reasons for wanting to do their duty.

Where an accountant follows a rule because it is required by an institution, it is still the case that they want to do their duty. The practice of following the rule can be called an institutional practice where it is done because following the rule is required by an institution whose authority is accepted. Auditing is an institutional practice in this sense. Auditors follow the rules in auditing standards, that is, accept that they have a duty to follow them, because they accept the authority of the standard setter. In some jurisdictions the practice of following rules for auditing might be a legal practice. This means that the reason why a rule is followed and a duty observed is that it is required by the law.

If one party wants something to be a duty of auditors, and institutions or legislatures do not, then the argument is not with auditors themselves but with the institutions or the legislatures that determine the duties of auditors. Of course, practising auditors may get involved with arguments about what should be their duty through their professional bodies. Unlike the expectations gap between the beliefs of nonauditors and those of auditors about what is a duty of auditors, the gap is between non-auditors and standard setters or the legislature about what the latter should require as a duty of auditors. Arguing about duties is a matter of looking at the reasons why institutions or the legislature want or do not want auditors to do certain things and at why other people want auditors to perform certain duties. The desires that prompt institutions or the legislature to promulgate rules about auditing might be described as objectives they have for the practice of auditing. The rules are believed to be a means of achieving these objectives. They are not objectives in the sense of some of Lee's objectives. They are not duties but are ends that will be achieved by auditors performing certain duties.

Institutions or the legislature might go through the following kind of practical reasoning:

I (=institutions/the legislature) want auditors to achieve objectives $\mathrm{Y}$

I believe that promulgating regulation/law $\mathrm{X}$ will achieve these objectives

I want to promulgate regulation/law $\mathrm{X}$

Arguing about what is wanted may involve considering reasons for wanting certain objectives expressed in the first premise. This involves further practical reasoning from other desires and beliefs about how these other desires will be fulfilled. It may also consider the second premise and dispute reasons for believing that certain regulations/laws will achieve these desires.

There is plenty of empirical evidence that some parties want auditors to perform certain duties that they are not at the moment required to do. Porter and Gowthorpe identify 46 responsibilities that 'society' expects auditors to perform of which only 13 are existing responsibilities of auditors. These expectations were identified by asking respondents about what responsibilities auditors 'should perform' (Porter \& Gowthorpe, 2004). This question amounts to asking respondents about the duties they want auditors to perform. Non-auditors may disagree about what they want. This may be because of differences in the reasons that each party has for wanting something to be a duty of auditors. The gap in duties might be called a 'duty gap'. The gap in reasons might be called a 'reasons gap'. The duty gap comes about as a result of a reasons gap. The latter might be characterized as arising because one party thinks the reasons are reasonable and another party thinks that they are not. The 'reasons gap' might be thought of as a 'reasonableness gap'. This distinction needs to be explored further.

\section{REASONABLENESS}

If regulators have reasons for wanting auditors to follow a rule and promulgate such a rule then it becomes a duty of auditors. Their reason for wanting auditors to follow a rule might come 
under scrutiny by others. If the belief or desire that together constitute this reason are not accepted by others, then the rule might be said to be unreasonable. Given that the reasons for wanting something involve further desires and beliefs about whether what is wanted will fulfil these desires, then whether or not the reasons given are taken as reasonable depends upon whether there is agreement on these further desires and beliefs. Agreement on reasonableness is agreement on reasons.

Porter states that 'in order for duties to be reasonably expected of auditors they must be cost-beneficial for auditors to perform' (Porter, 1993, p. 62). This means that rules should be promulgated, at least in part, only if they meet the desire for the benefits of following the rule to outweigh the costs associated with following it. It is suggested that 'it is logical that their performance should be cost-beneficial' (Porter \& Gowthorpe, 2004 , p. 38). In fact, there is nothing intrinsically 'logical' about the desire for the benefits of auditing to outweigh costs. It is simply something that is wanted and accepted as a reason for wanting auditing procedures to be established as a duty for auditors. The desire itself is not 'logical'. Something is logical only if it follows from premises in accordance with rules of logic. If a conclusion follows in accordance with the canons of practical reasoning, then it is 'logical' to accept the conclusion on the basis of accepting the premises. The premise itself, the desire for benefits to outweigh costs, is not itself logical. A premise expressing a desire is acceptable if the desire is accepted. Accepting a desire is a matter of either accepting it as desirable in itself or having reasons for wanting it of the kind that are expressed in further practical reasoning. A premise expressing a belief is acceptable if there is evidence for its truth. If both premises are accepted and the reasoning is sound then wanting to promulgate a standard is reasonable.

Whether or not a particular regulation that sets out a duty of auditors will fulfil a desire is an empirical matter. It is not the kind of thing about which agreement can be sought in general terms in advance of the proposal to establish particular duties. However, it is possible to agree in advance on the desires that are acceptable and that constitute reasons for the acceptance of a desire to promulgate duties. The criterion proposed by Porter of only accepting duties that are cost-beneficial is fine as far as it goes. However, to be operational the various parties who are concerned must agree on what constitutes a benefit and agree on the costs associated with it. They must also agree on some method of weighing the one against the other to establish that the benefit outweighs the cost. Although costs might be understood in terms of audit fees, what is to be taken as a benefit? Porter avoids the problems that might arise in identifying benefits by simply accepting that the duties that can be 'reasonably expected' are the duties expected by 'auditees and financial community audit beneficiaries' (Porter, 1993, p. 62). The assumption is that that they are motivated by cost-benefit considerations and so whatever duties they want auditors to perform will be cost-beneficial. This begs the question of whether the cost-benefit criterion is the only objective that is to be accepted in deciding on duties. There is also the question of whether their interpretation of something as a benefit coincides with that of other interested parties. It also begs the question of whether auditees and financial community audit beneficiaries are motivated only by such a criterion in deciding what duties are wanted of auditors. What is required is some agreement on what the objectives of auditing are or, what is the same thing, an agreement on what is wanted from auditing and auditors. This is necessary if there is to be agreement on whether or not it is reasonable to want auditors to have a certain duty. If other groups want something different then their desires are discounted and do not constitute 'reasonable' desires for the purpose of determining the duties of auditors. Some agreement on objectives is necessary if there is to be agreement on reasonableness.

\section{THE OBJECTIVES OF AUDITING}

According to Sikka et al. (1998) and Power (1997) there is no agreement on the objectives of auditing. The expectations gap is said to arise because of a disagreement about objectives. In so far as there is a lack of agreement about why certain objectives are wanted there is a 'reasons gap'. The attempt to achieve agreement about objectives in the context of financial reporting was one of the motivations for undertaking the project of developing a conceptual framework for financial reporting. This suggests that a way of bridging the 'reasons gap' is by undertaking a similar project for auditing. Undertaking such a project was suggested by a number of respondents in their comment letters on 
the Clarity Exposure Draft and Consultation Paper issued by the International Auditing and Assurance Standards Board (IAASB) in September 2004 (see comment letters of the International Organisation of Securities Commission, KPMG and PricewaterhouseCoopers in IAASB, 2005a).

Looking for reasons for auditing procedures is also something explored in what has been called a 'theory of auditing'. A 'theory' in this context is said to be a 'number of basic assumptions and a body of integrated ideas, the understanding of which will be of direct assistance in the development and practice of the art of auditing' (Mautz \& Sharaf, 1961, p. 1). Such a 'theory' considers 'the reasons for the use of various procedures as well as the steps in the procedures themselves, the "why" as well as the "how" as it is so often described" (Mautz \& Sharaf, 1961, p. 3). This might be re-expressed as an investigation into what is wanted from such procedures, that is, into the objectives that such procedures are meant to fulfil. This would constitute the desire aspect of reasons for promulgating regulations. Specific procedures might be derived from an 'assumption' about desires if a premise was added that expressed a belief that a certain procedure would meet the desire. These assumptions are referred to as 'postulates of auditing'. This is taken as the 'starting point for the development of a structure of audit theory' (Flint, 1988, p. 20). They are the 'foundation for the construction of a theory of auditing and the formulation of principles of practice' (Flint, 1988, p. 21).

The Fédération des Experts Comptables Européens (FEE) Issues Paper Principles of Assurance: Fundamental theoretical issues with respect to assurance in assurance engagements is concerned with developing what it also calls a 'foundation' for assurance engagements of the kind that are undertaken in audits (FEE, 2003, p. vi). This can be understood in the sense of something that will provide reasons, of the kind that constitute premises in practical reasoning, for requiring auditors to undertake certain auditing procedures. The Institut der Wirtschaftsprüfer (IdW) specifically identifies fundamental principles underlying an ISA audit with 'reasons' that lie behind the objectives expressed in auditing standards in their comment letter to the Clarity Exposure Draft and Consultation Paper mentioned above (IAASB, 2005b, p. 50). The point of constructing a 'foundation' is to get agreement on the desires that will constitute part of the reason for deciding what duties are to be required of auditors. Thinking about the objectives of auditing amounts to thinking about what is wanted from auditing and auditors. The duties that are required from auditors will be those that will result in the objectives of users being met. These objectives for auditing would be used in practical reasoning of the kind:

I want auditing to provide information $X$ to users (=the objectives of auditing)

I believe that requiring auditors to do $\mathrm{Y}$ will result in information $X$ being provided to users

I want auditors to do $Y$

I believe that by establishing a regulation that requires auditors to do $\mathrm{Y}$ they will do $\mathrm{Y}$

I want to establish a regulation requiring auditors to do $\mathrm{Y}$

As a result, $\mathrm{Y}$ becomes a duty of auditors and agreement on objectives is required because they constitute part of the reason for regulators choosing to promulgate standards. Without agreement on objectives then there may be a gap in what regulators want auditors' duties to be and what others want them to be. Agreeing on what is wanted from auditing and auditors is also relevant in determining the meaning of 'auditing'.

\section{THE MEANING OF 'AUDITING'}

One of the characterizations of the expectations gap referred to above was that it arises due to differences in the meaning of 'auditing'. A number of writers have drawn attention to vagueness and ambiguity in the meaning of expressions used in the discipline of auditing. Lee draws attention to the use of 'labels' in determining the nature of the audit function and their 'undefined nature' which gives rise to 'the vagueness of the descriptions of the associated body of knowledge' (Lee, 1994, p. 32). The auditing profession uses these in the social construction of the auditing profession' (Lee, 1994, p. 31). Power observes that 'there is no precise agreement about what auditing really is ... It is wiser to speak of a cluster of definitions which overlap but are not identical' (Power, 1997, p. 4). There are 'competing meanings of audit' and 'the 'social practice of "audit" does not have a single unambiguous meaning but rather, numerous competing meanings that exist side by side' (Sikka et al., 1998, p. 303). Lee ties this 
ambiguity to the expectations gap and argues that 'the lack of definition and clarity in this area can be argued to accentuate the audit expectations gap' (Lee, 1994, p. 33).

If expectations arise because of different understandings of the meaning of 'audit' and 'auditing' then this can have consequences for what auditors are required to do. Consider the following reasoning by an auditing standard setter or a legislator:

I want auditors to audit.

'Audit' means an activity that involves auditors doing $\mathrm{X}, \mathrm{Y}$ and $\mathrm{Z}$.

I believe that promulgating regulations/laws requiring auditors to do $\mathrm{X}, \mathrm{Y}$ and $\mathrm{Z}$ will result in auditors auditing.

I want to promulgate $\mathrm{X}, \mathrm{Y}$ and $\mathrm{Z}$.

If someone else has a different definition of 'audit' then they may expect the regulator to impose different duties on auditors. They may reason as follows:

'Audit' means an activity that involves auditors doing $\mathrm{A}, \mathrm{B}$ and $\mathrm{C}$.

Auditors will do what is required by regulators in the audits they undertake.

Regulators promulgate regulations/laws that require auditors to do $\mathrm{A}, \mathrm{B}$ and $\mathrm{C}$.

Auditors will do A, B and C.

These parties may expect regulators to define 'audit' in the same way that they do. This may result in them believing that certain things are the duties of auditors when they are not because the regulators, having a different definition of 'audit', require auditors to do different things. This may result in a gap in beliefs about what auditors do. Even if the gap in beliefs is addressed by pointing out that regulators do not define 'audit' in the same way and, hence, do not establish certain duties of auditors, there may still be a desire for auditors to do A, B and $\mathrm{C}$ and also a desire to establish a definition of 'audit' which involves such activities.

Wittgenstein claims that sentences that give the meaning of expressions give rules for the meaning of the expressions in the sentence (Baker \& Hacker, 1980, p. 36). Justifying such statements is a matter of justifying the acceptance of a rule. Given the 'naturalistic' view of language referred to above, exploring the reasons for following rules of language is a matter of setting it in the particular context in which it emerged. In the realm of accounting, Lyas (1993) suggests that concepts are evaluated from the perspective of the ends of accounting. In the case of the practice of auditing it is a matter of identifying the ends or objectives of auditing that constitute part of the reason for adopting a rule for the meaning of auditing expressions including the meaning of 'audit' itself. If parties adopt different rules for the meaning of 'audit' then bridging the gap that results is a matter of considering the reasons why these parties either do or do not accept the rule for the meaning of 'audit'. This comes down to getting agreement on what is wanted from auditing and involves the same sort of consideration of objectives as was indicated above. If one wants auditing to achieve certain objectives then one way to achieve them is by defining 'auditing' or 'audit' such that auditors can only be said to be doing auditing or conducting an audit if they achieve these objectives, that is, agreeing on what is wanted from auditing.

What also becomes clear is the potential difficulty involved in this endeavour. The meaning of 'audit' is 'contingent and negotiable: its fixing within relations of power is precarious and subject to redefinition. In practice, the struggle over meaning concerns not only the connotations associated with audit (or other social practices), but a struggle for access to, and control over, the institutions and arena in which connotations are negotiated and transformed' (Sikka et al., 1998, p. 304). The meaning of 'audit' is contested because there are disagreements in what is wanted from auditing. The expectation gap in meaning again arises from this source. Given the differences in what is wanted, the elimination of the gap might not be possible. Unless there can be agreement on what is wanted there may be no agreement on what 'audit' means. Hines (1989) argues that constructing a conceptual framework which might consider matters of this kind is itself performed in a political arena. Political considerations may also result in contesting the definition of 'audit'. The contest is actually over what is wanted from auditing. If language is 'naturalistic then progress in getting agreement on meanings requires an understanding of the context in which the concepts arose and the human interests and needs that determine how the practice of using expressions with meanings develops. Unless this is appreciated then it is unlikely that much progress will be reached on agreeing the meaning of 'audit'. 
If expectations are understood as desires then the expectations gap might be characterized as a gap between:

(i) desires for auditors to have certain duties in an audit

(ii) reasons for wanting auditors to have certain duties in an audit

(iii) definitions of 'audit' and 'auditing'

(iv) reasons for wanting to define 'audit' and 'auditing' in a certain way.

The desires in (i) are based on the reasons in (ii). These reasons include desires for auditing and audits to achieve certain ends or objectives. It is these ends and objectives that constitute the reasons for wanting to define 'audit' and 'auditing' in a certain way in (iv) and result in the different definitions in (iii).

\section{RECONFIGURING THE EXPECTATIONS GAP}

Characterizing the expectations gap as a gap in expectations does not clearly bring out the real nature of the issues involved. The word 'expects' suggests that expectations are beliefs about what auditors will do in the future. What is often meant by talking about expectations in the literature is that parties have general beliefs about what auditors do that are not solely related to what they will do. These beliefs are based on beliefs about the duties of auditors. Others statements about expectations suggest that they are not entirely beliefs about what auditors will do but express desires for auditors to perform procedures or be given duties or to perform such procedures or duties in a particular way. This suggests that expectations gaps can be more perspicuously analysed in terms of differences in beliefs and desires.

As an example of how this analysis might be applied, Porter's characterization of the expectations gap can be re-described in terms of beliefs and desires. The 'reasonableness gap' may be a gap between what regulators and legislators want auditors to do and what 'society' wants auditors to do. The gap in desires arises due to a difference in the reasons each party has for wanting auditors to do something. These reasons may be characterized as 'unreasonable' and give rise to 'unreasonable expectations' if there is a gap in reasons. To get agreement about what is wanted from auditors there has to be agreement on reasons, that is, on what is 'reasonable'. If the reasons are 'reasonable' and the standard setter has not established a duty to do something then the standard setter has produced 'deficient standards' and there is a 'deficient standards gap'. Society may believe auditors have a duty because they assume that standard setters want auditors to do what is reasonable and promulgate standards that require them to perform certain procedures. It may be that this belief is false. Auditors who follow these standards will not end up doing what it is 'reasonable' to want them to do if there is no standard requiring them to perform some duty. There may be a gap in what society believes auditors do and what they do. If the standard setter has promulgated standards that it is reasonable to want auditors to follow, then it is reasonable to believe that they will follow them. If auditors do not follow them, that is, there is 'deficient performance', then the belief is false and the desire that they follow the standards is not fulfilled. There may be a 'performance gap'.

\section{CONCLUSION}

The use of the term 'expects' is misleading and should be replaced by talk of beliefs and desires. This ties in very well with the characterization of the expectations gap as a variance in 'beliefs and desires' (Humphrey et al., 1992a, p. 2). Reconfiguring the expectations gap in this way and identifying the reasons for these beliefs and desires makes it clearer how such gaps might be bridged. Reasons for beliefs are different from reasons for desires and these are understood in relation to different kinds of reasoning. Only some of the expectations gap issues can be tackled by examining the evidence for beliefs about what auditors do or about their duties. If beliefs are based on ignorance then the solution is to educate the parties that have mistaken beliefs. This is often the response of the profession to expectations gap issues. If expectations are desires then the gaps need to be examined by considering the practical reasoning from objectives to these desires. The nature of such reasoning has been explained in this paper. It was suggested that progress in agreeing on what is wanted from auditors and auditing may have to await agreement on the objectives of auditing. Expectations gap issues will not be resolved without a clear grasp of the kind of expectations that are involved.

Reconfiguring the gap in this way should also help to clarify the nature of the empirical work 
about the gap and suggest further avenues for research. Questionnaires in such work focus on asking the respondents whether something is an existing responsibility of auditors and on how well the existing responsibility is performed. Further questions ask whether auditors should perform this responsibility (Porter, 1993; Porter \& Gowthorpe, 2004). The first two questions try to determine beliefs about what auditors do and how well they do it. The second address the question of desires, of what is wanted from auditors. If the questions were addressed in terms of beliefs and desires, this might then prompt researchers to explore the reasons for respondents wanting auditors to fulfil duties. This is not explored in current research.

It is interesting to speculate as to why the distinction is not made between expectations that are beliefs and expectations that are desires. One explanation is that the absence of 'conceptual considerations' in auditing, as in financial reporting (Power, 1993, p. 44), has meant that the idea of an expectation has not been very closely examined. Another explanation is that it has suited the auditing profession to characterize the expectations gap as a gap in beliefs and not to accept that it may arise due to a gap in desires. If 'audit objectives are constructed and transformed within social relations of power' (Sikka et al., 1998, p. 299) then masking a debate about desires by representing it as debate about beliefs may serve to "disarm critics and preserve the territorial claims of the profession' (Sikka et al., 1998, p. 321). This conveniently avoids potentially embarrassing demands being made of the practice of auditing that the profession has no desire to fulfil. It also avoids recognizing that it might not be possible to achieve agreement on what is wanted from auditing. Just as the meaning of 'audit' develops in a professional context so the expression 'expectations gap' develops in such a context. It may be that the vagueness in the use of this expression and the related expressions of 'expectations' and 'expects' suits certain parties in this context. Perhaps 'the persistence of ambiguity seems to serve a purpose' (Page \& Spira, 2005, p. 301). The fact that there may be a purpose does not mean that it is a good purpose. If the profession is serious in wanting to address the problems of the expectations gap, it needs to acknowledge the real nature of the expectations. This paper suggests that the question 'What do you expect?' when asked of those who have expectations about auditing should be replaced by the questions 'What do you believe?' and 'What do you want?'. If this is done then the nature of expectations becomes clearer and a start can be made on a proper debate about the expectations gap.

\section{NOTE}

1. Even the name varies from one writer to the next. In the context of audit it has been characterized as the 'expectations gap' (Humphrey et al., 1992a; Sikka et al., 1998), the 'expectation-performance gap' (Porter, 1993), the 'expectation gaps' (ICAEW, 2006a) and 'the expectation gap' (in various other writers see references in Porter \& Gowthorpe, 2004). In this paper these terms are taken as synonymous and the term 'expectations gap' is used to refer to the issues grouped around these expressions.

\section{REFERENCES}

Anscombe, G. E. M. (1957), Intention, Oxford: Basil Blackwell.

APB (2007), The Auditor's Report: A Time for Change? Discussion Paper. London: The Auditing Practices Board.

Archer, S. (1993), On the methodology of constructing a conceptual framework for financial accounting. In Mumford, M. \& Peasnell, K. (eds.), Philosophical Perspectives on Accounting, London: Routledge.

Baker, G. P. \& Hacker, P. M. S. (1980), Wittgenstein Meaning and Understanding, Oxford: Blackwell.

Chandler, R. \& Edwards, J. R. (1996), 'Recurring issues in auditing: back to the future?', Accounting, Auditing $\mathcal{E}$ Accountability Journal, Vol. 9, No. 2, pp. 4-29.

Davidson, D. (1980), Actions, reasons and causes. In Davidson, D., Essays on Actions and Events, Oxford: Oxford University Press.

Dennis, I. (2008), 'A conceptual enquiry into the concept of a "principles-based" accounting standard', British Accounting Review, Vol. 40, pp. 260-71.

FEE (2003), Principles of Assurance: Fundamental theoretical issues with respect to assurance in assurance engagements, Issues Paper, Brussels: Fédération des Experts Comptables Européens.

Flint, D. (1988), Philosophy and Principles of Auditing: An Introduction, London: Macmillan Education Ltd.

Gaa, J. (1991), 'The expectations game: regulation of auditors by government and the profession', Critical Perspectives in Accounting, Vol. 2, pp. 83-107.

Gillies, D. (1993), Philosophy of Science in the Twentieth Century - Four Central Themes, Oxford: Blackwell.

Goldman, A. I. (1970), A Theory of Human Action, Princeton, NJ: Princeton University Press.

Hacker, P. M. S. (1996), Wittgenstein Mind and Will Part I Essays, Oxford: Blackwell. 
Hines, R. D. (1989), 'Financial accounting knowledge, conceptual framework projects and the social construction of the accounting profession', Accounting, Auditing and Accountability Journal, Vol. 2, No. 2, pp. 72-92.

Humphrey, C. (1997), Debating audit expectations. In Sherer, M. \& Turley, S. (eds), Current Issues in Auditing, 3rd edn, London: Paul Chapman Publishing Ltd.

Humphrey, C., Moizer, P. \& Turley, S. (1992a), The Audit Expectations Gap in the United Kingdom, London: ICAEW.

Humphrey, C., Moizer, P. \& Turley, S. (1992b), 'The audit expectations gap - plus ça change, plus c'est la même chose?', Critical Perspectives in Accounting, Vol. 3, pp. 137-61.

Humphrey, C., Moizer, P. \& Turley, S. (1993), 'The audit expectations gap in Britain: an empirical investigation', Accounting and Business Research, Vol. 23, pp. 395-411.

IAASB (2005a), 'Clarity ED and Consultation Paper Respondents' Comments - General Statements' [Online]. Retrieved on 6 May 2009 from http:// www.ifac.org/IAASB/Meeting-BGPapers.php? $\mathrm{MID}=0038 \&$ ViewCat $=0288$.

IAASB (2005b), 'Comments Received on Clarity Consultation Paper' [Online]. Retrieved on 6 May 2009 from http://www.ifac.org/IAASB/ Meeting-BGPapers.php?MID=0038\&ViewCat=0295

ICAEW (2006a), Audit Quality Fundamentals - Audit Purpose, London: ICAEW.

ICAEW (2006b), Professional Stage Learning Outcomes 2007, Milton Keynes: ICAEW.

IFAC (2007), 'Tomorrow is already here: the evolution of audit quality', Presentation by Fermín del Valle, President of the International Federation of Accountants at FAR SRS Annual Seminar 'ARENA 2007' in Stockholm, 30 November 2007 [Online]. Retrieved on 26 November 2008 from http:// www.ifac.org/MediaCenter/?q=node/view /523

Lee, T. A. (1970), 'The nature of auditing and its objectives', Accountancy, Vol. 81, No. 920, pp. 292-6.

Lee, T. A. (1994), 'Financial reporting quality labels', Accounting, Auditing \& Accountability Journal, Vol. 7, No. 2, pp. 30-49.

Lyas, C. (1993), Accounting and language. In Mumford, M. \& Peasnell, K. (eds), Philosophical Perspectives on Accounting, London: Routledge.

Mattessich, R. (1995), 'Conditional-normative accounting methodology: incorporating value judgements and means-end relations of an applied science', Accounting, Organizations and Society, Vol. 20, No. 4, pp. 259-84.
Mautz, R. K. \& Sharaf, H. A. (1961), Philosophy of Auditing, Sarasota, FL: American Accounting Association.

Page, M. \& Spira, L. (2005), 'Ethical codes, independence and the conservation of ambiguity', Business Ethics: A European Review, Vol. 13, No. 3, pp. 301-16.

Porter, B. (1993), 'An empirical study of the audit expectation-performance gap', Accounting and Business Research, Vol. 24, No. 93, pp. 49-69.

Porter, B. \& Gowthorpe, C. (2004), Audit Expectations Performance Gap in the United Kingdom in 1999 and Comparison with the Gap in New Zealand in 1989 and in 1999, Edinburgh: ICAS.

Power, M. (1993), On the idea of a conceptual framework for financial reporting. In Mumford, M. \& Peasnell, K. (eds), Philosophical Perspectives on Accounting, London: Routledge.

Power, M. (1997), The Audit Society, Oxford: Oxford University Press.

Searle, J. R. (1995), The Construction of Social Reality, London: Penguin Books.

Sikka, P., Puxty, A., Willmott, H. \& Cooper, C. (1998), 'The impossibility of eliminating the expectations gap: some theory and evidence', Critical Perspectives in Accounting, Vol. 9, pp. 299-330.

Sterling, R. (1993), The subject matters of accounting. In Mumford, M. \& Peasnell, K. (eds), Philosophical Perspectives on Accounting, London: Routledge.

Teo, E-J. \& Cobbin, P. E. (2005), 'A revisitation of the "audit expectations gap": judicial and practitioner views on the role of the auditor in late-Victorian England', Accounting History, Vol. 10, No. 2, pp. 35-66.

Wikipedia (2008), England expects that every man will do his duty, available from http://en.wikipedia.org/ wiki/England_expects_that_every_man_will_do_ his_duty (Accessed 16 April 2008).

Wittgenstein, L. (1958), Philosophical Investigations, 2nd edition, Oxford: Basil Blackwell.

Wolfram, S. (1989), Philosophical Logic: An Introduction, London: Routledge.

\section{AUTHOR PROFILE}

Ian Dennis is a Senior Lecturer in Accounting, Financial Reporting and Auditing at the Business School, Oxford Brookes University. His research interests include auditing, conceptual frameworks and philosophical aspects of financial reporting and auditing. 